\title{
Development and analytical performance evaluation of an automated chemiluminescent immunoassay for pro-gastrin releasing peptide (ProGRP)
}

\author{
Toru Yoshimura ${ }^{1, *}$, Kenju Fujita ${ }^{1}$, Hideki \\ Kinukawa', Yoshiharu Matsuoka', Rahul D. \\ Patil $^{2}$, Gangamani S. Beligere ${ }^{2}$, Sabrina S. \\ Chan $^{2}$, Barry L. Dowell², Lori Sokoll ${ }^{3}$, Debra \\ Elliott ${ }^{3}$, Daniel W. Chan ${ }^{3}$, Cornelia Scheuer ${ }^{4}$, \\ Karin Hofmann ${ }^{4}$, Petra Stieber ${ }^{4}$, Yousuke \\ Sakurai ${ }^{5}$, Masayuki lizuka ${ }^{5}$, Haruhisa Saegusa ${ }^{5}$ \\ and Ken Yamaguchi ${ }^{6}$ \\ ${ }^{1}$ Diagnostics Division, Abbott Japan, Matsudo-City, \\ Chiba, Japan \\ ${ }^{2}$ Diagnostics Division, Abbott Laboratories, Lake \\ County, IL, USA \\ ${ }^{3}$ Department of Pathology, The Johns Hopkins \\ University, Baltimore, USA \\ ${ }^{4}$ Institute of Clinical Chemistry, University of \\ Munich, Munich, Germany \\ ${ }^{5}$ Denka Seiken, Gosen-City, Niigata, Japan \\ ${ }^{6}$ Shizuoka Cancer Center, Nagaizumi-cho, Shizuoka, \\ Japan
}

\begin{abstract}
Background: Pro-gastrin releasing peptide (ProGRP) concentrations in blood play an important role in the diagnosis and treatment of patients with small cell lung cancer (SCLC). The automated quantitative ARCHITECT ${ }^{\circledR}$ ProGRP assay was developed to aid in the differential diagnosis and in the management of SCLC. The purpose of this study was to evaluate the analytical performance of this chemiluminescent microparticle immunoassay at multiple sites.

Methods: ARCHITECT ProGRP measures ProGRP using a two-step sandwich using monoclonal antiProGRP antibodies coated on paramagnetic microparticles and labeled with acridinium. Analytical performance of the assay was evaluated at four sites: Abbott Japan, Denka Seiken, the Johns Hopkins University, and the University of Munich.

Results: Total precision (\%CV) for nine analyte concentrations was between 2.2 and 5.7. The analytical sensitivity of the assay was between $0.20 \mathrm{pg} / \mathrm{mL}$ and $0.88 \mathrm{pg} / \mathrm{mL}$. The functional sensitivity at $20 \% \mathrm{CV}$ was between $0.66 \mathrm{pg} / \mathrm{mL}$ and $1.73 \mathrm{pg} / \mathrm{mL}$. The assay was linear up to $50,000 \mathrm{pg} / \mathrm{mL}$ using a 1:10 autodilution protocol. The calibration curve was stable for 30 days. Comparison with the Fujirebio microtiter plate

*Corresponding author: Toru Yoshimura, Research and Development, Diagnostics Division, Abbott Japan, 278 Matsuhidai, Matsudo, Chiba, Japan Phone: +81-47-386-4805, Fax: +81-47-386-4257, E-mail: tohru.yoshimura@abbott.com Received May 13, 2009; accepted August 11, 2009; previously published online October 13, 2009
\end{abstract}

enzyme-linked immunosorbent assay (EIA) ProGRP assay gave a slope of 0.93 and a correlation coefficient $(r)$ of 0.99 .

Conclusions: These results demonstrate that the ARCHITECT ProGRP assay has excellent sensitivity, precision, and correlation to a reference method. This assay provides a convenient automated method for ProGRP measurement in serum and plasma in hospitals and clinical laboratories.

Clin Chem Lab Med 2009;47:1557-63.

Keywords: automated immunoassay; chemiluminescent microparticle immunoassay; pro-gastrin releasing peptide; small cell lung cancer; tumor marker.

\section{Introduction}

Pro-gastrin releasing peptide (ProGRP) is a tumor marker for small cell lung cancer (SCLC). ProGRP is used to aid in the diagnosis and monitoring of SCLC. Gastrin releasing peptide (GRP) is a gut hormone and is widely distributed in the mammalian gastrointestinal tract, nervous system and pulmonary tract (1-4). It was reported that GRP was often produced by SCLC cells, and therefore could be helpful in the diagnosis of $\operatorname{SCLC}(5,6)$. However, GRP was not useful for diagnosis due to poor stability in specimens. Three types of human ProGRP were found in SCLC cells, with 115, 118 , and 125 amino acids (7). ProGRP consists of GRP (residues 1-27), a cleavage site (residues 28-30), a constant region (residues 31-98) in the three types of ProGRP, and a variable carboxy-terminal region that results from alternative RNA splicing $(7,8)$.

In 1994, an assay to detect ProGRP (residues 31-98) in serum was developed because the molecule was more stable than GRP for clinical use, and increases in ProGRP were associated with the presence of SCLC (9-11). The clinical usefulness of ProGRP 31-98 measurements has been reported for diagnosis $(9,11-13)$, prediction of prognosis (14), and monitoring of treatment in patients with SCLC $(11,15-17)$. Neuronspecific enolase (NSE) has been also used as a tumor marker for SCLC. However, compared to NSE, ProGRP has relatively high sensitivity and specificity, and allows early recognition of relapse in patients with $\operatorname{SCLC}(11,18,19)$. Also, it was reported that a combination of ProGRP and NSE gave increased sensitivity for detection of $\operatorname{SCLC}(12,19)$. The ProGRP immunoassay was originally developed as a manual enzyme-linked immunosorbent assay format using polyclonal and monoclonal antibodies $(10,11)$. The assay has been used in the clinical laboratories in 
Japan for more than 10 years. However, it has not been used outside of Japan except for research use. For worldwide clinical use, the following two improvements would be required: development of an assay for widely used fully-automated immunoassay analyzers, and use of monoclonal antibodies for both solid phase and labeled antibodies to assure long-term reagent reliability.

We describe the development of a fully automated and highly sensitive immunoassay for the Abbott ARCHITECT ${ }^{\circledR}$ ProGRP (Abbott Japan, Tokyo, Japan). We used a double monoclonal antibody assay configuration for both solid phase and labeled antibody, with chemiluminescense paramagnetic technology. We describe the analytical performance of this assay as evaluated at four sites in the US, Germany and Japan.

\section{Materials and methods}

The ARCHITECT ProGRP assay is a two-step, sandwich format. Analyte capture is performed with paramagnetic microparticles coated with two mouse monoclonal anti-ProGRP 31-98 antibodies: 3G2 (amino acids of ProGRP 84-88) and 2B10 (amino acids of 71-75) (20), which can capture the C-terminal side of ProGRP 31-98. Detection of the ProGRP analyte microparticle complex is accomplished with an acridinium labeled mouse monoclonal antibody conjugate. The mouse monoclonal antibody 3D6-2 (20) can capture the Nterminal side of the protein (amino acids of ProGRP 40-60). The antibody profile of the assay is shown in Figure 1. Exposing the reaction mixture to on-board trigger reagents containing peroxide at alkaline $\mathrm{pH}$ causes light production that is proportional to the ProGRP concentration. The ARCHITECT ProGRP assay calibrators range from $0 \mathrm{pg} / \mathrm{mL}$ to $5000 \mathrm{pg} / \mathrm{mL}(0,20,80,320,1250$, and $5000 \mathrm{pg} / \mathrm{mL})$. A 1:10 autodilution is used to extend the measurable range to $50,000 \mathrm{pg} / \mathrm{mL}$. ARCHITECT ProGRP control concentrations are 40,160 , and $2500 \mathrm{pg} / \mathrm{mL}$. To minimize the risk of interference from human-anti-mouse antibodies, heterophile antibodies, and rheumatoid factor, blocking agents and murine mAbs of different isotypes are used in the assay. In addition, the $F\left(a b^{\prime}\right) 2$ portion of the antibody, with the Fc portion eliminated by pepsin digestion, was used to produce the conjugate. The assay is fully automated and measurement is completed within $30 \mathrm{~min}$ with a throughput of $200 \mathrm{tests} / \mathrm{h}$.

\section{ARCHITECT ProGRP assay protocol}

The following procedures are performed automatically in the ARCHITECT instrument: 1) $50 \mu \mathrm{L}$ of specimen, $50 \mu \mathrm{L}$ of microparticle solution, and $20 \mu \mathrm{L}$ of assay buffer are mixed and incubated for $18 \mathrm{~min}$ at $37^{\circ} \mathrm{C}$. 2) After a wash step, $50 \mu \mathrm{L}$ of solution containing the labeled antibody is mixed and incubated for $4 \mathrm{~min}$ at $37^{\circ} \mathrm{C}$. 3) After another wash step, the trigger reagent is added and the luminescent signal is read using a photomultiplier tube. For a 1:10 autodilution, wash buffer on the instrument is used to dilute the sample.

\section{ProGRP antigen and concentration assignment}

Synthetic ProGRP (residues 31-98) peptide ( $1 \mathrm{pg} / \mathrm{mL}$ equals $0.13 \mathrm{pM}$ of ProGRP 31-98) was used for the antigen of the ARCHITECT calibrator and control reagents (BACHEM Bioscience Inc, Horizon Drive, King of Prussia, PA, USA). Since there is no International Standard for ProGRP, the ARCHITECT ProGRP assay was standardized to match to the original standard (9) by comparison to the Seramurabo ProGRP assay kit originally developed by Yamaguchi and co-workers (9-11).

\section{ProGRP monoclonal antibodies}

Hybridomas of the murine anti-ProGRP 31-98 monoclonal antibodies 3G2, 2B10, and 3D6-2 were provided by Advanced Life Science Institute, Inc (ALSI; Wako, Japan). The hybridomas were cultured in serum free media and antibodies were purified with a protein A column from the supernatants at Abbott Laboratories (Lake County, IL, USA).

\section{Magnetic microparticles}

Murine anti-ProGRP 31-98 antibodies of $3 \mathrm{G} 2$ and 2B10 were coated on to the carboxylated magnetic microparticle (Polymer Laboratories, Shropshire, UK) surface with N-Ethyl$\mathrm{N}^{\prime}$-(3-Dimethylaminopropyl)carbodiimide (Sigma-Aldrich, St. Louis, MO, USA) as a coupling substance. The coating with two antibodies increased analytical sensitivity of the assay $\sim 10$ fold when compared to use of a single monoclonal antibody.

\section{Specimens}

SCLC specimens were obtained from Johns Hopkins University, ProMeDx, LLC (Norton, MA, USA), Clinical Research Center of Cape Cod, Inc (West Yarmouth, MA, USA), and Teragenix (Ft. Lauderdale, FL, USA). Normal specimens from

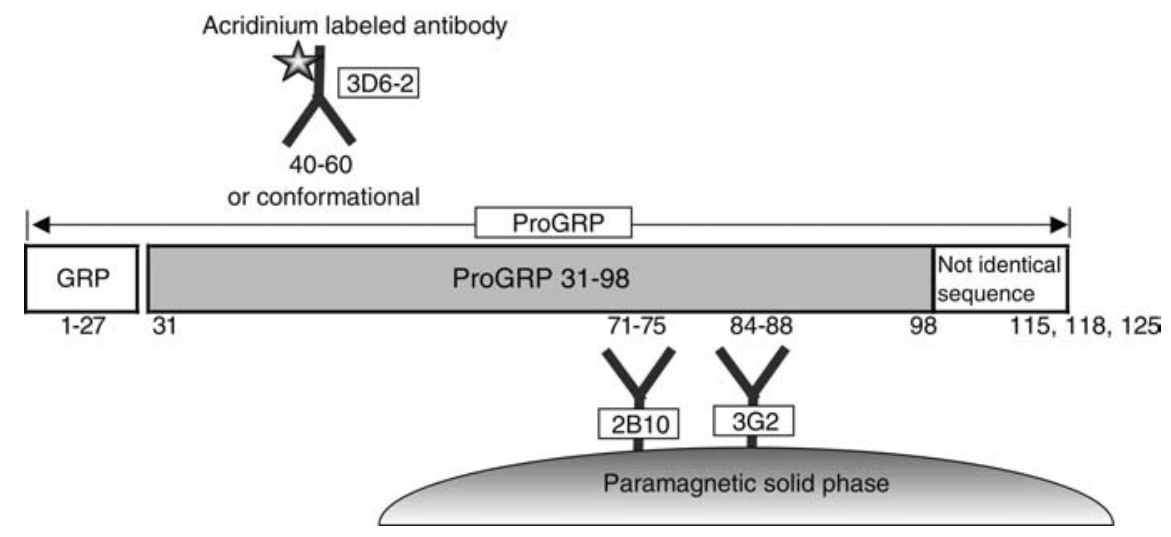

Figure 1 Format of the ARCHITECT ProGRP assay. 
apparently healthy individuals were obtained from ProMeDx, LLC. These specimens were stored frozen at $-20^{\circ} \mathrm{C}$ or colder until use. The specimens were collected under an institutional review board approved protocol.

\section{Evaluation methods}

Precision was evaluated using serum and plasma specimens spiked with synthetic ProGRP 31-98 antigen and the ARCHITECT ProGRP controls. These were measured in duplicate, two times per day for 20 days in accordance with the Clinical and Laboratory Standards Institute (CLSI, protocol EP5-A2). A high plasma specimen spiked with synthetic ProGRP $31-98$ antigen at $\sim 30,000 \mathrm{pg} / \mathrm{mL}$ level was tested using the 1:10 autodilution protocol.

Dilution linearity studies were conducted with native high titer serum specimens $(614 \mathrm{pg} / \mathrm{mL}$ and $3337 \mathrm{pg} / \mathrm{mL})$ and with serum (276-4676 pg/mL) and plasma (226-4931 pg/mL) specimens spiked with synthetic ProGRP 31-98 antigen. Specimens were serially diluted in $10 \%$ increments with the ARCHITECT A calibrator ( $0 \mathrm{pg} / \mathrm{mL}$ ProGRP). Regression analyses of the observed diluted concentrations were compared to target values based on the corresponding concentration of the undiluted specimen.

We evaluated manual vs. automated dilutions by calculating the $\%$ difference of a instrument-diluted specimen (1:10 on the ARCHITECT system) compared with a manually diluted specimens. Specimens containing more than $5000 \mathrm{pg} / \mathrm{mL}$ of ProGRP (three of native high titer SCLC sera, four of serum and seven plasma specimens spiked with ProGRP 31-98) were evaluated.

Within-assay specimen carryover was tested by alternating a low serum specimen ( $\sim 10 \mathrm{pg} / \mathrm{mL}$ ProGRP) with a high serum specimen $(\sim 110,000 \mathrm{pg} / \mathrm{mL})$ spiked with ProGRP $31-98$, and repeated 10 times. The $\%$ carryover was determined by calculating the \% difference in value of the low specimen run immediately after the high specimen.

The absence of a high-dose hook effect was confirmed by testing specimens beyond the dynamic range of the assay $(5000 \mathrm{pg} / \mathrm{mL}$ ) up to $100,000 \mathrm{pg} / \mathrm{mL}$ to determine whether signal suppression occurs at analyte levels exceeding the concentration levels of the assay calibration.

Analytical sensitivity was determined with five runs of ten replicates of the A calibrator $(0 \mathrm{pg} / \mathrm{mL})$ and four replicates of B calibrator $(20 \mathrm{pg} / \mathrm{mL})$. The following calculation was used: analytical sensitivity $=$ standard deviation (SD) A calibrator $\times$ $2 \times[20 \mathrm{pg} / \mathrm{mL}$ B calibrator level/(B calibrator average relative light unit (RLU) - A calibrator average RLU)].

The functional sensitivity was evaluated using a set of dilution panels made by diluting a normal specimen with the $A$ calibrator. The panel members were tested in replicates of 10 for 5 days. The ProGRP concentration that showed 20\% $\mathrm{CV}$ with linear least square regression plotted between total precision (\%CV) and (1/ProGRP concentration) was defined as the functional sensitivity.

Recovery was evaluated by spiking ProGRP from a hightiter serum from a patient with SCLC into matched serum, ethylenediaminetetraacetic acid (EDTA) plasma and heparin plasma samples. The ProGRP values were measured with the ARCHITECT ProGRP assay. Percent recovery was calculated using the following formula: $(\%$ recovery $)=[$ (observed concentration of sample spiked ProGRP serum)-(concentration of the unspiked sample)]/(ProGRP concentration added). Note that calibrator buffer was added to the unspiked sample to maintain the same volume as the spiked sample.

Reagent on-board stability studies were conducted using serum and plasma specimens spiked with synthetic ProGRP 31-98 antigen and the ARCHITECT ProGRP controls. A cali-

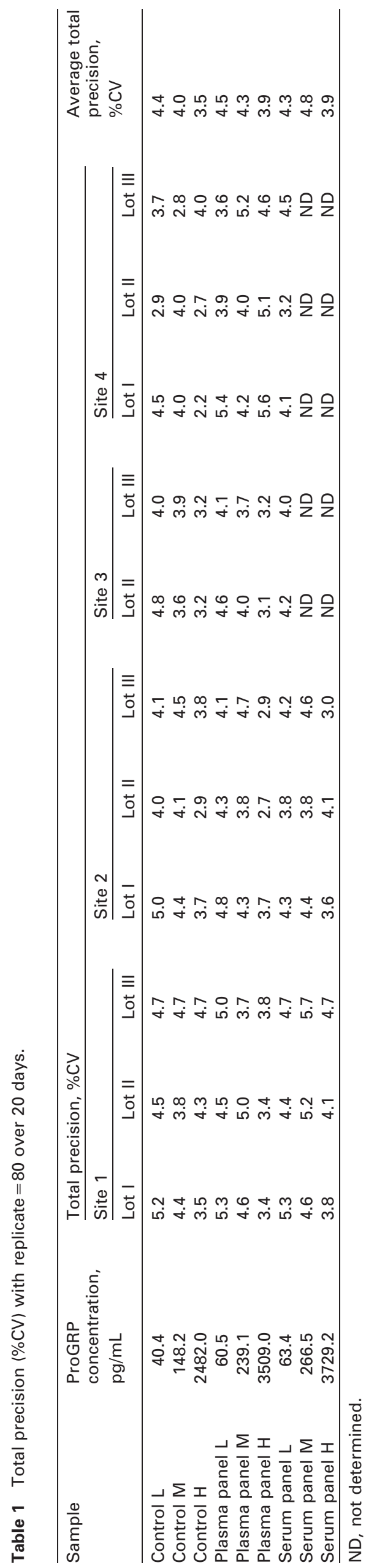


Table 2 Analytical sensitivity and functional sensitivity at $20 \% \mathrm{CV}$.

(A) Analytical sensitivity with 2 SD method

\begin{tabular}{|c|c|c|c|}
\hline & \multicolumn{3}{|c|}{ Analytical sensitivity, $\mathrm{pg} / \mathrm{mL}$} \\
\hline & Lot I & Lot II & Lot III \\
\hline Site 1 (Instrument 1) & 0.20 & 0.21 & 0.25 \\
\hline Site 1 (Instrument 2) & 0.27 & 0.23 & 0.40 \\
\hline Site 3 (Instrument 3) & 0.88 & 0.51 & 0.60 \\
\hline Average & & & 0.39 \\
\hline \multicolumn{4}{|c|}{ (B) Functional sensitivity at $20 \% \mathrm{CV}$} \\
\hline & \multicolumn{3}{|c|}{ Functional sensitivity, $\mathrm{pg} / \mathrm{mL}$} \\
\hline & Lot I & Lot II & Lot III \\
\hline Site 1 (Instrument 1) & 0.68 & 0.66 & 0.92 \\
\hline Site 1 (Instrument 2) & 1.25 & 1.03 & 1.17 \\
\hline Site 3 (Instrument 3) & 1.73 & 1.16 & 1.61 \\
\hline
\end{tabular}

Table 3 Recovery of ProGRP spiked into EDTA plasma, heparin plasma, and serum.

\begin{tabular}{|c|c|c|c|}
\hline \multirow[t]{3}{*}{ Specimen type } & \multicolumn{2}{|l|}{ Recovery } & \multirow[t]{3}{*}{ Average recovery, $\%$} \\
\hline & \multicolumn{2}{|c|}{ Spiked ProGRP concentration } & \\
\hline & $50 \mathrm{pg} / \mathrm{mL}, \%$ & $150 \mathrm{pg} / \mathrm{mL}, \%$ & \\
\hline EDTA plasma-1 & 91.3 & 92.5 & \\
\hline EDTA plasma-2 & 95.6 & 94.3 & \\
\hline EDTA plasma-3 & 92.0 & 95.7 & 93.9 \\
\hline EDTA plasma-4 & 96.2 & 92.2 & \\
\hline EDTA plasma-5 & 96.6 & 92.8 & \\
\hline Heparin plasma- 1 & 95.8 & 98.4 & \\
\hline Heparin plasma-2 & 95.5 & 98.7 & \\
\hline Heparin plasma-3 & 104.5 & 102.1 & 97.8 \\
\hline Heparin plasma-4 & 97.3 & 96.9 & \\
\hline Heparin plasma-5 & 96.0 & 93.2 & \\
\hline Serum-1 & 88.9 & 87.2 & \\
\hline Serum-2 & 91.9 & 97.7 & \\
\hline Serum-3 & 96.5 & 97.0 & 92.8 \\
\hline Serum-4 & 91.2 & 91.2 & \\
\hline Serum-5 & 92.3 & 93.6 & \\
\hline
\end{tabular}

bration curve was established at the initiation of the 31 days study and used to generate concentrations for each samples with reagents stored at $2-8^{\circ} \mathrm{C}$ off the instrument (Control), and stored at $2-8^{\circ} \mathrm{C}$ on-board the instrument for the duration of the study (Test). Baseline was calculated as the mean of the first five timepoints with the control reagent. Specimen and control concentrations were evaluated for trending over time in control and test reagents using Westgard rules (21).

Calibration curve storage was calculated using data generated from the control reagents tested for on-board stability. The percent change in RLUs and concentrations for specimens tested on day 31 were compared to the RLUs and concentrations from the calibration performed at the initiation of the study.

Assay interferences were evaluated using chemotherapeutic drugs at two times their peak blood level, with common interfering substances and GRP, as shown in Table 4. Though amino acid sequence between GRP and ProGRP 31-98 is completely different, interference of large amounts of GRP was evaluated to confirm that there was no cross reactivity to GRP. Each drug or potentially interfering substance was tested in three normal serum specimens and three normal plasma specimens spiked with 50 or $150 \mathrm{pg} / \mathrm{mL}$ of ProGRP from a high-titer specimen. Ten replicates were tested on the ARCHITECT ProGRP assay for each of the test and control specimens.
Correlation between the microtiter plate enzyme immunoassay of the Seramurabo ProGRP assay from Fuji-rebio (Tokyo, Japan) and the ARCHITECT ProGRP was evaluated using 64 SCLC and 192 normal specimens. The first ProGRP assay was co-developed by the National Cancer Center (Tokyo, Japan), Terumo Corp. (Kanagawa, Japan), and Tonen Corp. (Saitama, Japan; 9, 10, 11, 13). The kit was approved for use in Japan as a diagnostic product and is now provided by Fuji-rebio. Also, the kit is available in Europe and the US as a research use only product provided by ALSI.

\section{Evaluation sites}

Evaluation was performed at four sites: (1) Abbott Japan (Matsudo-city, Chiba, Japan), (2) Denka Seiken (Gosencity, Niigata, Japan), (3) The Johns Hopkins University (Baltimore, Maryland, USA) and (4) University of Munich (Munich, Germany).

\section{Results}

Total precision for the ARCHITECT ProGRP assay evaluated over 20 days at four sites with three lots of 

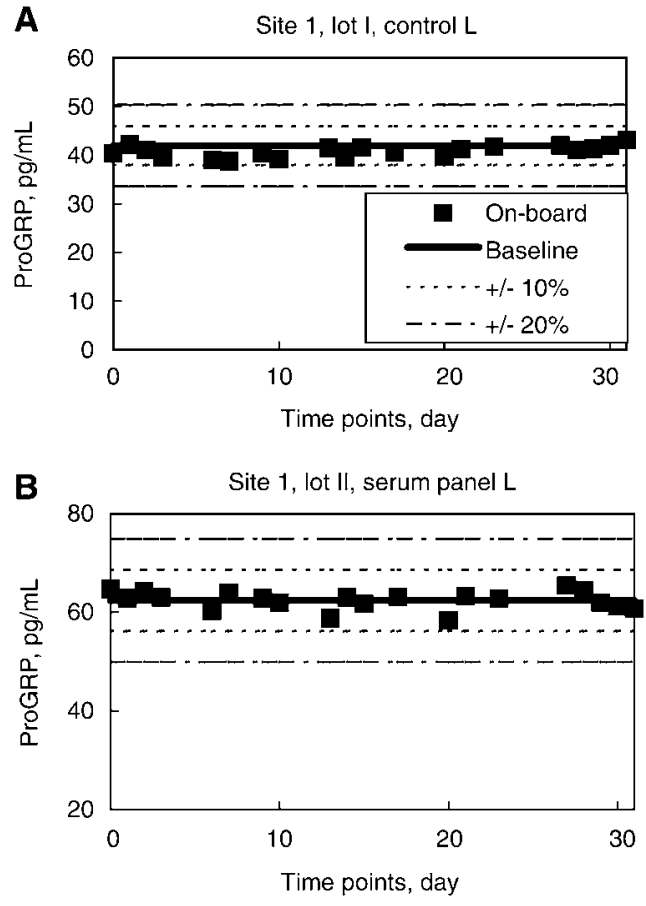

Figure 2 Reagent on-board instrument stability with control $\mathrm{L}$ and serum panel $\mathrm{L}$.

reagents on four instruments, and using nine specimens ranging from 40 to $3729 \mathrm{pg} / \mathrm{mL}$ is shown in Table 1. The total precision ranged from $2.2 \%$ to $5.7 \%$ $\mathrm{CV}$ for serum and plasma. The total precision for the automated dilution evaluated at one site with three lots of reagents on two instruments ranged from $3.7 \%$ to $5.1 \%$ CV using specimens spiked to contain $28,972 \mathrm{pg} / \mathrm{mL}$ ProGRP. The average 1:10 autodilution protocol results were $-5.8 \%$ and $-7.6 \%$ of the manually diluted results with six sera and seven plasma specimens, respectively, using native and spiked specimens contained between 6220 and $40,491 \mathrm{pg} / \mathrm{mL}$ of ProGRP.

Dilution linearity studies using specimens with concentrations ranging from 25.8 to $4931 \mathrm{pg} / \mathrm{mL}$ showed correlation coefficients ranging from 0.9964 to 0.9994 . Mean recoveries of diluted samples ranged from $93 \%$ to $107 \%$ (average $103 \%$ ) in six spiked serum specimens, and $98 \%$ to $111 \%$ (average $102 \%$ ) in six spiked plasma specimens. Mean recoveries of two SCLC sera were $102 \%$ and $104 \%$. Dilutions were linear throughout the calibration curve range down to the lowest calibrator. The ARCHITECT ProGRP assay dilutes linearly with a mean recovery $2.6 \%$ from the target.

The mean within-assay specimen carryover evaluated with two instruments was $2.1 \mathrm{pg} / \mathrm{mL}$ (19 ppm) after a specimen with $110,000 \mathrm{pg} / \mathrm{mL}$.

Assessment of high dose hook effect showed that all five specimens with ProGRP $>5000 \mathrm{pg} / \mathrm{mL}$ yielded test results $>5000 \mathrm{pg} / \mathrm{mL}$. No signal suppression or high dose hook effect was observed up to 100,000 $\mathrm{pg} / \mathrm{mL}$.

Analytical sensitivity and the functional sensitivity evaluated at two sites with three lots of reagents on three instruments are shown in Table $2 \mathrm{~A}$ and $\mathrm{B}$. The average analytical sensitivity was $0.39 \mathrm{pg} / \mathrm{mL}$ and ranged from 0.20 to $0.88 \mathrm{pg} / \mathrm{mL}$. The average functional sensitivity at a $20 \% \mathrm{CV}$ was $1.13 \mathrm{pg} / \mathrm{mL}$ and ranged from 0.66 to $1.73 \mathrm{pg} / \mathrm{mL}$.

The calculated recovery in the ARCHITECT ProGRP assay after spiking a high-titer ProGRP specimen into matched serum, EDTA plasma, and heparin plasma specimens is shown in Table 3. The average percent recovery was $92.8 \%, 93.9 \%$, and $97.8 \%$ with serum, EDTA plasma, and heparin plasma, respectively.

Reagent on-board stability studies were conducted at two sites with three lots of reagents using two instruments and nine specimens with low, medium,

Table 4 Evaluation of common interfering substances, anticancer chemotherapeutic drugs, and GRP.

\begin{tabular}{|c|c|c|c|}
\hline & \multicolumn{3}{|c|}{ Interference } \\
\hline & \multicolumn{2}{|c|}{ Specimen type } & \multirow[t]{2}{*}{ Average, \% } \\
\hline & Serum, \% & Plasma, \% & \\
\hline Bilirubin, $20 \mathrm{mg} / \mathrm{dL}(0.34 \mu \mathrm{mol} / \mathrm{L})$ & 0.3 & 0.2 & 0.3 \\
\hline Hemoglobin, $5 \mathrm{~g} / \mathrm{L}$ & -8.5 & -3.5 & -6.0 \\
\hline Total protein, $120 \mathrm{~g} / \mathrm{L}$ & -2.0 & -2.2 & -2.1 \\
\hline Total protein, $30 \mathrm{~g} / \mathrm{L}$ & -2.5 & -2.8 & -2.7 \\
\hline Red blood cells, $4 \mu \mathrm{L} / \mathrm{mL}$ & ND & -4.9 & -4.9 \\
\hline Triglycerides, $30 \mathrm{~g} / \mathrm{L}$ & 3.9 & 5.9 & 4.9 \\
\hline Carboplatin, $110.8 \mu \mathrm{g} / \mathrm{mL}$ & -0.9 & -0.3 & -0.6 \\
\hline Cisplatin, $7.24 \mu \mathrm{g} / \mathrm{mL}$ & 0.4 & -1.1 & -0.3 \\
\hline Cyclophosphamide, $4.08 \mu \mathrm{g} / \mathrm{mL}$ & -1.3 & 2.2 & 0.4 \\
\hline Docetaxel, $4.6 \mu / \mathrm{mL}$ & -0.5 & -1.2 & -0.8 \\
\hline Doxorubicin, $360 \mu \mathrm{M}$ & -1.3 & -0.2 & -0.7 \\
\hline Etoposide, $80 \mu \mathrm{g} / \mathrm{mL}$ & -0.8 & 0.3 & -0.2 \\
\hline Gemcitabine, $43.7 \mu \mathrm{g} / \mathrm{mL}$ & 0.5 & 0.5 & 0.5 \\
\hline Ifosfamide, $0.78 \mu \mathrm{g} / \mathrm{mL}$ & 1.9 & 0.0 & 0.9 \\
\hline Irinotecan, $11.5 \mu \mathrm{g} / \mathrm{mL}$ & 0.8 & -0.2 & 0.3 \\
\hline Paclitaxel, $13.5 \mathrm{ng} / \mathrm{mL}$ & 2.1 & -1.5 & 0.3 \\
\hline Topotecan, $172.2 \mathrm{ng} / \mathrm{mL}$ & 2.2 & 2.0 & 2.1 \\
\hline Vincristine, $140 \mathrm{ng} / \mathrm{mL}$ & 1.0 & 0.4 & 0.7 \\
\hline Vinorelbine, $2000 \mathrm{ng} / \mathrm{mL}$ & 0.3 & 0.4 & 0.3 \\
\hline GRP, 100 ng/mL & 1.1 & 1.2 & 1.2 \\
\hline
\end{tabular}

ND, not determined. 


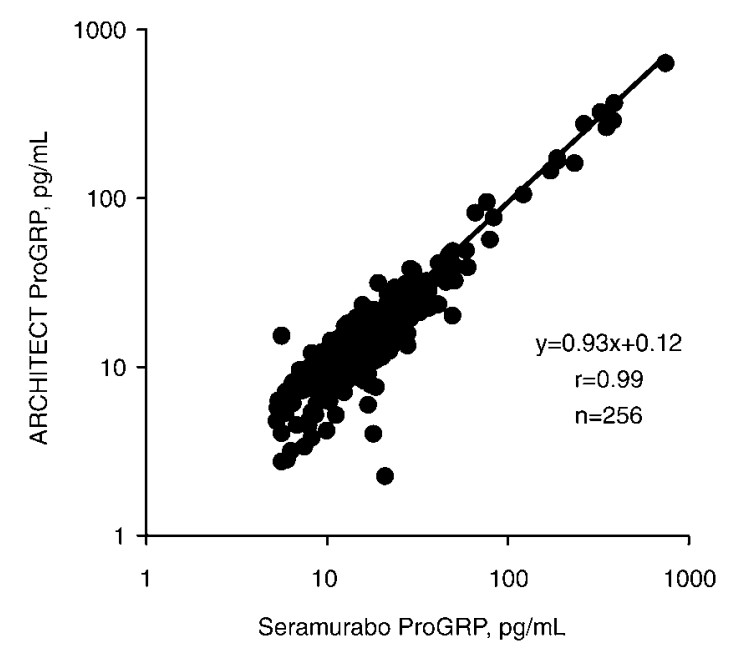

Figure 3 Correlation between the manual Seramurabo ProGRP EIA assay and the ARCHITECT ProGRP assay.

and high concentrations of spiked serum and plasma, and ARCHITECT controls. Results showed no significant changes from study baseline up to 30 days using Westgard rules. Two examples of the results are illustrated in Figure $2 \mathrm{~A}$ and $\mathrm{B}$.

The effects of potential interfering substances and drugs are presented in Table 4. Chemotherapeutic agents at twice their peak blood levels had interferences of $-0.8 \%$ to $+2.1 \%$. Increased bilirubin, total protein, triglycerides, red blood cells and hemoglobin, and low total protein showed interference effects from $-6.0 \%$ to $+4.9 \%$.

Correlation between the first commercial ProGRP assay, Seramurabo ProGRP, and the ARCHITECT ProGRP is presented in Figure 3. The slope, calculated using the Passing-Bablok regression method was 0.93 with a correlation coefficient of $r=0.99$.

\section{Discussion}

ProGRP is used as a marker for the differential diagnosis and monitoring of SCLC. It is important to distinguish between SCLC and non-SCLC due to differences in prognosis and treatment. SCLC accounts for $15 \%-25 \%$ of new cases of lung cancer, is an aggressive and rapidly growing neoplasm that tends to be disseminated at early stage of the disease. However, this cancer is highly sensitive to systemic chemotherapy. ProGRP was developed as a tumor marker in 1994 for patients with SCLC (9). It has been clinically used as a tumor marker in Japan since 1996 for aid in the diagnosis, monitoring of treatment, and early detection of relapse. However, it has been available as a research-use only manual assay outside of Japan. This tumor marker plays a very important role in the management of this cancer. The development of this fully automated immunoassay using monoclonal antibodies can support the global use of ProGRP for management of SCLC.

The multi-site evaluation studies for the ARCHITECT ProGRP assay reported here demonstrated good anaIytical precision, accuracy and sensitivity. The assay has a range, with the 1:10 autodilution, of 50,000 $\mathrm{pg} / \mathrm{mL}$, with no hook effect observed at 100,000 $\mathrm{pg} / \mathrm{mL}$. The reagents and calibration curve were stable onboard the instrument for 30 days. The assay demonstrated robustness to potential interfering substances including chemotherapeutic drugs and a variety of compounds commonly assessed for interference in immunoassays. The assay correlated well to the existing manual ProGRP assay.

The ARCHITECT ProGRP assay was designed to be used with plasma as well as serum samples. The assay demonstrates good recovery, dilution linearity and precision with plasma. The ability to test plasma ProGRP is important based on the recent observations demonstrating improved specimen stability for plasma ProGRP when compared to serum ProGRP (22).

In conclusion, the ARCHITECT ProGRP assay demonstrated convenient, high throughput and good analytical performance necessary for ProGRP measurements used to aid in the differential diagnosis and monitoring of SCLC. This assay provides a convenient automated method for measurement of ProGRP in serum and plasma in hospitals and clinical laboratories. Additional clinical studies in Europe and Japan using the ARCHITECT ProGRP are currently underway to better define its use for the management of patients with SCLC.

\section{Conflict of interest}

The following authors are employees of Abbott Laboratories which market the ARCHITECT ProGRP assay: Toru Yoshimura, Kenju Fujita, Hideki Kinukawa, Yoshiharu Matsuoka, Rahul D. Patil, Gangamani S. Beligere, Sabrina S. Chan, and Barry L. Dowell. Abbott Laboratories supplied funding to perform assay evaluation to the following authors: Lori Sokoll, Debra Elliott, Daniel W. Chan, Cornelia Scheuer, Karin Hofmann, and Petra Stieber. The following authors are employees of Denka Seiken, which manufactures the ARCHITECT ProGRP assay under contract with Abbott Laboratories: Yousuke Sakurai, Masayuki lizuka, and Haruhisa Saegusa. Ken Yamaguchi owns the patent for ProGRP which was licensed to Abbott through ALSI. Ken Yamaguchi is a president of Shizuoka Cancer Center that Abbott Laboratories is collaborating for clinical evaluation of the ARCHITECT ProGRP. There are no other conflicts of interest.

\section{Acknowledgements}

We wish to acknowledge the efforts of Shunichiro Ogura and Toru Mochizuki from Shizuoka Cancer center, Toyoharu Fukutani, Noboru Maki, and Tetsuo Itoh from Advanced Life Science Institute, Inc, Jack Ramp, Brenda Calfin, Eddie Eng, Jon Ryan, Tracey Rae, You Pan, Troy McSherry, Richard Scopp and members of the Specimen Bank from Abbott Laboratories, Satoshi Kawakami, Makoto Komori, Eiji Kobayashi and Katsumichi Takeda from Abbott Japan.

\section{References}

1. McDonald TJ, Nilsson G, Vagne M, Gjatei M, Bloom SR, Mutt $V$. A gastrin releasing peptide from the porcine nonantral gastric tissue. Gut 1978;19:767-74. 
2. Cuttitta F, Carney DN, Mulshine J, Moody TW, Fischker A, Minna JD. Autocrine growth factors in human small cell lung cancer. Cancer Surv 1985;4:707-27.

3. Ghatei MA, Bloom SR, Langevin H, Mc Gregor GP, Lee $Y C$, Adraian TE, et al. Regional distribution of bombesin and seven other regulatory peptides in the human brain. Brain Res 1984;293:101-9.

4. Tsutsumi Y, Nagara H, Watanabe K, Yanaihara N. Immunoreactivity of $\mathrm{N}$-terminal fragment of gastrin releasing peptide as histochemical marker for pancreatobility duct-type cells. Lab Invest 1984;50:94-100.

5. Yamaguchi K, Abe K, Kameya T, Adachi I, Taguchi S, Otsubo K, et al. Production and molecular size heterogeneity of immunoreactive gastrin-releasing peptide in fetal and adult lungs and primary lung tumors. Cancer Res 1983;43:3932-9.

6. Maruno K, Yamaguchi K, Abe K, Suzuki M, Saijo N, Mishima $Y$, et al. Immunoreactive gastrin-releasing peptide as a specific tumor marker in patients with small cell lung carcinoma. Cancer Res 1989;49:629-32.

7. Sausville ED, Lebacq-Verheyden A, Spindel ER, Cuttitta F, Gazdar AF, Battey JF. Expression of the gastrin-releasing peptide gene in human small cell lung cancer. J Biol Chem 1986;261:2451-7.

8. Reeve JR, Cuttitta F, Vigna SR, Heubner V, Lee TD, Shiverly JE, et al. Multiple gastrin-releasing peptide geneassociated peptides are produced by a human small cell lung cancer line. J Biol Chem 1988;263:1928-32.

9. Miyake M, Kodama T, Yamaguchi K. Pro-gastrin-releasing peptide (31-98) is a specific tumor marker in patients with small cell lung carcinoma. Cancer Res 1994;54: 2136-40.

10. Aoyagi A, Miyake Y, Urakami K, Kashiwakuma T, Hasegawa $A$, Kodama $T$, et al. Enzyme immunoassay of immunoreactive progastrin-releasing peptide (31-98) as tumor marker for small-cell lung carcinoma: development and evaluation. Clin Chem 1995;41:537-43.

11. Yamaguchi K, Aoyagi K, Urakami K, Fukutani T, Maki N, Yamamoto S, et al. Enzyme-linked immunosorbent assay of pro-gastrin-releasing peptide for small cell lung cancer patients in comparison with neuron-specific enolase measurement. Jpn J Cancer Res 1995;86:698-705.
12. Stieber $P$, Dienemann $H$, Schalhorn A, Schmitt UM, Reinmiedl J, Hofmann K, et al. Pro-gastrin-releasing peptide (ProGRP) - a useful marker in small cell lung carcinomas. Anticancer Res 1999;19:2673-8.

13. Kodama T, Abe S, Yamaguchi K, Eguchi K, Saigenji K, Kameya $T$, et al. Clinical significance for diagnosis of serum ProGRP by enzyme-linked immunosorbent assay (ELISA). Med Pharmaceut Sci 1994;32:87-97.

14. Shibayama T, Ueoka H, Nishi K, Kiura K, Tabata M, Miyatake $\mathrm{K}$, et al. Complementary role of pro-gastrin-releasing peptide (ProGRP) and neuron specific enolase (NSE) in diagnosis and prognosis of small-cell lung cancer (SCLC). Lung Cancer 2001;32:61-9.

15. Sunaga N, Tsuchiya S, Minato K, Watanabe S, Fueki N, Hoshino $\mathrm{H}$, et al. Serum pro-gastrin-releasing peptide is a useful marker for treatment monitoring and survival in small-cell lung cancer. Oncology 1999;57:143-8.

16. Schneider J, Philipp M, Velcovsky HG, Morr H, Katz N. Pro-gastrin-releasing peptide (ProGRP), neuron specific enolase (NSE), carcinoembryonic antigen (CEA) and cytokeratin 19-fragments (CYFRA 21-1) in patients with lung cancer comparison to other lung diseases. Anticancer Res 2003;23:885-94.

17. Schneider J, Philipp M, Salewski L, Velcovsky HG. Progastrin-releasing peptide (ProGRP) and neuron specific enolae (NSE) in therapy control of patients with smallcell lung cancer. Clin Lab 2003;49:35-42.

18. Okusaka T, Eguchi K, Kasai T, Kurata T, Yamamoto N, Ohe $Y$, et al. Serum levels of Pro-gastrin-releasing peptide for follow-up of patients with small cell lung cancer. Clin Cancer Res 1997;3:123-7.

19. Molina R, Filella $X$, Auge JM. ProGRP: a new biomarker for small cell lung cancer. Clin Biochem 2004;37:505-11.

20. Aoyagi K. Antibody directed against gastrin-releasing peptide precursor and use thereof. European patent application EP1876445A1. 2008:1-19.

21. Westgard JO, Barry PL, Hunt MR. A multi-rule Shewhart chart for quality control in clinical chemistry. Clin Chem 1981;27:493-501.

22. Yoshimura T, Fujita K, Kawakami S, Takeda K, Chan S, Beligere G, et al. Stability of pro-gastrin releasing peptide (ProGRP) in serum vs. plasma. Tumor Biol 2008;29: 224-30. 